\title{
Puccinia caxiuanensis sp. nov. de Uredinales em espécies de Burseraceae no Brasil
}

\author{
Helen Maria Pontes Sotão ${ }^{1,4}$, Joe Fleetwood Hennen² e Denise Vilela de Rezende ${ }^{3}$
}

Recebido: 12.06.2007; aceito: 02.10.2007

\begin{abstract}
Puccinia caxiuanensis sp. nov. of Uredinales on species of Burseraceae in Brazil). Puccinia caxiuanensis, collected in National Forest of Caxiuanã, State of Pará, Brazil, is described as a new species of Uredinales (rust fungi) on Crepidospermum goudotianum (Tul) Triana \& Planch. and Tetragastris panamensis (Engl.) Kuntze (Burseraceae).
\end{abstract}

Key words: Amazônia, Basidiomycota, Caxiuanã, rust fungi

RESUMO - (Puccinia caxiuanensis sp. nov. de Uredinales em espécies de Burseraceae no Brasil). Descreve-se Puccinia caxiuanensis, coletada na Floresta Nacional de Caxiuanã, Estado do Pará, Brasil, como uma nova espécie de Uredinales (ferrugem) sobre Crepidospermum goudotianum (Tul) Triana \& Planch. e Tetragastris panamensis (Engl.) Kuntze (Burseraceae).

Palavras-chave: Amazônia, Basidiomycota, Caxiuanã, ferrugem

\section{Introdução}

Puccinia Pers. ex Pers. é o maior gênero da ordem Uredinales, classificado na família Pucciniaceae Chevall., com cerca de 4.000 espécies (Cummins \& Hiratsuka 2003), entre nomes válidos e sinônimos. De acordo com Hennen et al. (2005), para o Brasil são conhecidas cerca de 300 espécies.

Para a Floresta Nacional de Caxiuanã (FLONA de Caxiuanã) os trabalhos publicados envolvendo fungos da ordem Uredinales são os de Sotão et al. (1997, 2006). Sotão (2001) apresentou, em tese de doutorado, estudo com 67 táxons para esta região, citando a espécie nova aqui descrita.

O presente trabalho é parte do inventário de fungos (Basidiomycota) da FLONA de Caxiuanã, cujo principal objetivo é contribuir com o aumento do conhecimento da diversidade de fungos da Amazônia.

\section{Material e métodos}

A FLONA de Caxiuanã está localizada nos municípios de Portel e Melgaço, no Estado do Pará

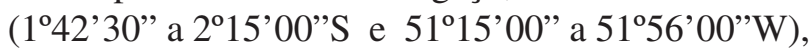
ocupando uma área de 330.000 ha. Segundo Almeida et al. (1993), é uma das áreas mais ricas da Amazônia, tanto em biodiversidade como em potencial florestal. Abrange diversos ecossistemas, destacando-se a floresta densa de terra firme (cerca de $80-90 \%$ do total) e as florestas de várzea e igapó.

Os métodos adotados neste trabalho para coleta, preservação e identificação, constam de Cummins \& Hiratsuka (2003). Para observação das microestruturas em microscópio óptico foram montadas lâminas semipermanentes de soros e esporos em solução de lactoglicerol. Para observação em microscopia eletrônica de varredura (MEV), as estruturas foram montadas em suportes de alumínio, com fita adesiva de carbono e metalizadas em ouro. Utilizou-se microscópio eletrônico LEO modelo 1450VP.

Os espécimes estão depositados no Herbário João Murça Pires (MG), na Coordenação de Botânica, do Museu Paraense Emílio Goeldi.

\section{Resultados e Discussão}

Puccinia caxiuanensis J.F. Hennen, Sotão \& Rezende sp. nov.

Figuras 1-3

Espermogoniis, aeciis et urediniis ignotis. Teliis, foliculis abaxialis in maculis flavis subepidermialibus

1. Museu Paraense Emílio Goeldi, Coordenação de Botânica, Caixa Postal 399, 66040-170 Belém, Pará, Brasil

2. Botanical Research Institute of Texas, 509 Pecan Street, Fort Worth, Texas 76102-4060 United States of América

3. Universidade de Brasília, Instituto de Ciências Biológicas, Departamento de Fitopatologia, 70919-900 Brasília, DF, Brasil

4. Autor para correspondência: helen@museu-goeldi.br 
vel erumpentibus, semi-circularibus, segregatis vel agregatis, ca. 0,1-0,25 mm diam., bruneis vel aureobruneis; sporis pedicelatis $(54-) 63-71 \times 14-17(-20) \mu \mathrm{m}$, oblongis vel clavatis, rotundatis vel obtusis in apice, rotundatis vel generatin angustis in basi, 2-cellulis, septis transversalibus; parietes $1,5-3 \mu \mathrm{m}$ crassitudine laterali, pariete crassa in apice 3-7 $\mu \mathrm{m}$, aureo-brunea, laevigata; poris germinalibus in cellula superiore apicali et in cellula basali laterali, pedicello hyalino, fragili.
Espermogônios, écios e uredínios não observados. Télios foliares, abaxiais, em manchas amareladas, subepidermais em origem, irrompentes, semicirculares, isolados ou agrupados, ca. 0,1-0,25 mm diâm., marrom a marrom-dourado; esporos pedicelados (54-)63-71 × 14-17(-20) $\mu \mathrm{m}$, oblongos a clavados, arredondados ou obtusos no ápice, arredondados ou geralmente estreitos na base, bicelulares, com septo transversal, parede 1,5-3 $\mu \mathrm{m}$

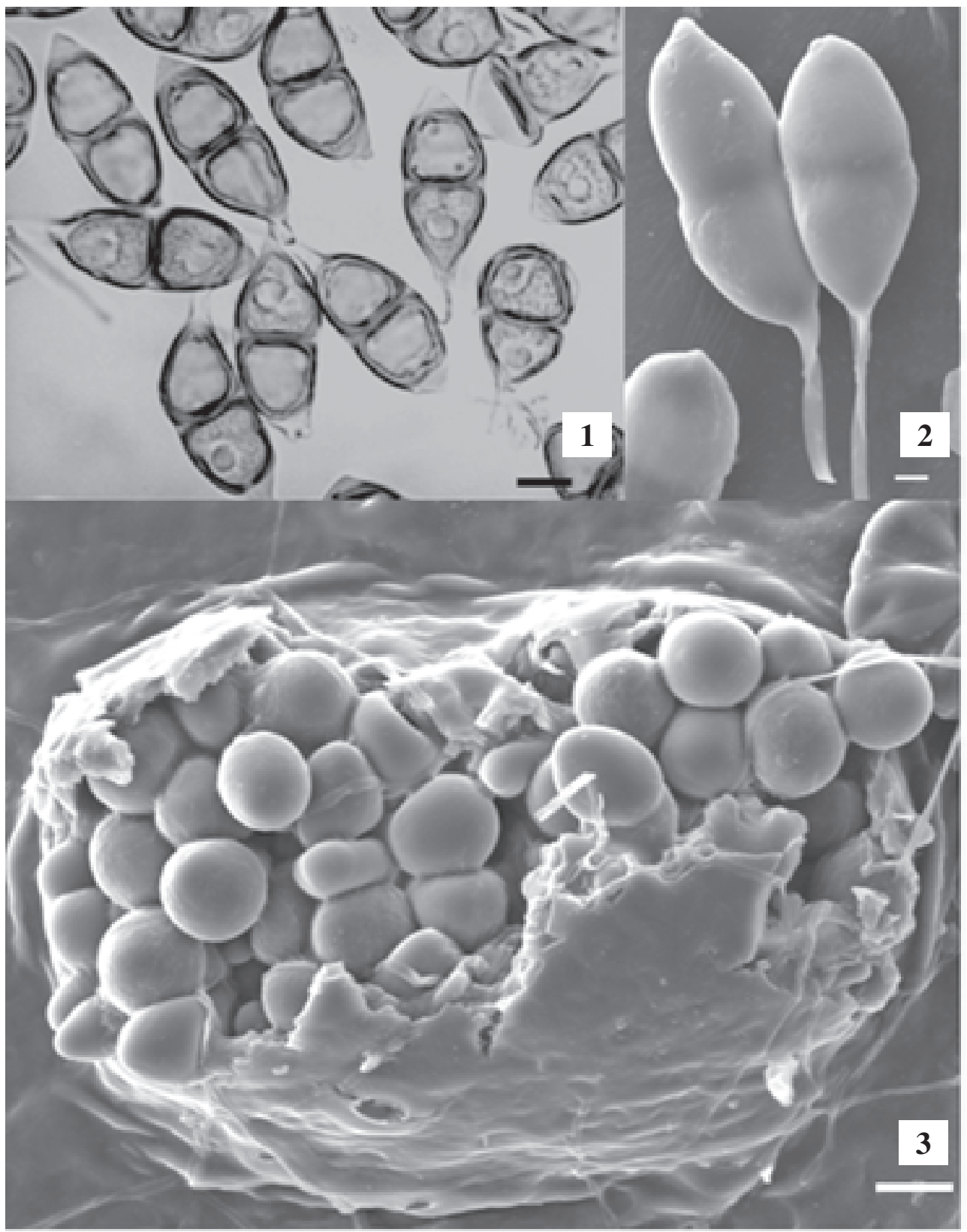

Figuras 1-3. Puccinia caxiuanensis 1. Teliósporos em MO (barra $=11 \mu \mathrm{m})$. 2. Teliósporos em MEV (barra $=5 \mu \mathrm{m}$ ). 3. Soro telial rompendo a epiderme do hospedeiro (barra $=10 \mu \mathrm{m}$ ). 
espessa lateral, 3-7 $\mu \mathrm{m}$ espessa no ápice, marromdourada, lisa; poros germinativos na célula superior de localização apical e na célula basal de localização lateral, pedicelo hialino, quebradiço.

TIPO: BRASIL. PARÁ: Melgaço, Floresta Nacional de Caxiuanã, Estação Científica Ferreira Penna, sobre Tetragastris panamensis (Engl.) Kuntze, Burseraceae, 28-V-1997, H. Sotão \& Hennen 97-361 (holótipo MG; isótipo BRIT).

PARÁTIPO: BRASIL. PARÁ: Melgaço, Floresta Nacional de Caxiuanã, Estação Científica Ferreira Penna, sobre Tetragastris panamensis (Engl.) Kuntze, Burseraceae, 2-X-2003, O. Cardoso et al. 1121 (MG); idem, O. Cardoso et al. 1129 (MG); idem, sobre Crepidospermum goudotianum (Tul) Triana \& Planch., 27-V-1997, H. Sotão \& Hennen 97-345 (MG, BRIT); 2-VI-1998, H. Sotão 98-109 (MG); 20-V-2002, H. Sotão et al. H2002-282 (MG).

Esta nova espécie foi coletada sobre dois gêneros da família Burseraceae, Crepidospermum e Tetragastris. Este é o primeiro registro de ferrugem sobre esses gêneros e representa a primeira ocorrência de ferrugem sobre representantes da família Burseraceae no Brasil. As referências de espécies de Uredinales conhecidas para a América do Sul em plantas da família Burseraceae são a de Hennings (1904), que descreveu Aecidium cerrense P. Henn. parasitando espécie do gênero Protium procedente do Peru e a de Buriticá (1999), que descreveu Phakopsora costaricensis Buriticá \& Hennen, com o anamorfo em Malupa burserae (Sydow) Buriticá \& Hennen, sobre o gênero Bursera, procedente da Costa Rica.

O epíteto específico da espécie aqui proposta faz referência à localidade de coleta do material tipo (Caxiuanã, Estado do Pará).

\section{Agradecimentos}

Agradecemos ao Museu Paraense Emílio GoeldiECFPn, pelo apoio logístico e financeiro; aos técnicos Luís Carlos Lobato e Osvaldo Cardoso, da Coordenação de Botânica do MPEG, pelo acompanhamento no campo e identificações das plantas hospedeiras e ao botânico Pe. José Maria Albuquerque, pela diagnose latina.

\section{Literatura citada}

Almeida, S.S., Lisboa, P.L.B. \& Silva, A.S.L. 1993. Diversidade florística de uma comunidade arbórea na Estação Científica "Ferreira Penna”, em Caxiuanã (Pará). Boletim do Museu Paraense Emílio Goeldi, Série Botânica, 9: 93-128.

Buriticá, P. 1999. La Família Phakopsoraceae en el Neotrópico III - Géneros: Batistopsora y Phakopsora. Revista de la Academia Colombiana de Ciencias Exactas, Físicas y Naturales 23: 271-305.

Cummins, G. B. \& Hiratsuka, Y. 2003. Illustrated Genera of Rust Fungi. 3 ed. American Phytopathological Society, Saint Paul.

Hennen, J.F., Figueiredo, M.B., Carvalho Júnior, A.A. \& Hennen, P.G. 2005. Catalogue of Plant Rust Fungi (Uredinales) of Brazil. http://www.jbrj.gov.br (acesso em 15.08.2007).

Hennings, P. 1904. Fungi amazonici - I. a cl. Ernesto Ule collecti. Hedwigia 43: 154-186.

Sotão, H.M.P. 2001. Uredinales da Floresta Nacional de Caxiuanã. Tese de Doutorado, Universidade Federal do Pará, Belém.

Sotão, H.M.P., França, I.F. \& Hennen, J.F. 2006. Fungos das famílias Phakopsoraceae e Uropyxidaceae (Uredinales) da Floresta Nacional de Caxiuanã, Pará, Brasil. Hoehnea 33: 407-417.

Sotão, H.M.P., Hennen, J.F., Gugliotta, A.M., Melo, O.A. \& Campos, E.L. 1997. Os fungos-Basidiomycotina. In: P.L. Lisboa (org.). Caxiuanã. Museu Paraense Emílio Goeldi, Belém, v. IV., pp. 213-219. 